TECHNICAL TRANSACTIONS 6/2018

MECHANICS

DOI: $10.4467 / 2353737$ XCT.18.095.8700 SUBMISSION OF THE FINAL VERSION: 11/06/2018

\author{
Halszka Skórska (halszkas@gmail.com) \\ Jerzy Sładek \\ Laboratory of Coordinate Metrology, Faculty of Mechanical Engineering, Cracow \\ University of Technology
}

\title{
A SIMULATION STUDY OF THE GRAPHICAL USER INTERFACE OF THE HEAD-UP DISPLAY AND ITS INFLUENCE ON THE DRIVER'S PERCEPTION
}

SYMULACYJNE BADANIE WPEYWU INTERFEJSU GRAFICZNEGO WYŚWIETLACZA TYPU HEAD-UP NA PERCEPCJĘ KIEROWCY

\begin{abstract}
This article presents the results of a simulation study of an augmented reality system and its influence on the user's perception and reaction time. An automotive head-up display was chosen to conduct this research. It was assumed that the configuration of the GUI influences the perception and response time of the user of the augmented reality system. The perception of the driver was tested by using an eye-tracking device with accompanying software. The optimal graphical user interface (GUI) was developed as a result of the research.

Keywords: augmented reality, head-up display, graphical user interface, simulation, perception, reaction time
\end{abstract}

\section{Streszczenie}

W artykule przedstawiono wyniki badań percepcji użytkownika systemu rzeczywistości rozszerzonej (AR) uzyskanych na podstawie przeprowadzonych symulacji. Na obiekt badań i symulacji wybrano wyświetlacz przezierny typu head-up stosowany w samochodach. Założono, że konfiguracja interfejsu graficznego systemu rzeczywistości rozszerzonej wplywa na percepcję i czas reakcji użytkownika systemu. Percepcję kierowcy zbadano, wykorzystując metodę śledzenia ruchu gałek ocznych i odpowiednie oprogramowanie. W wyniku badań opracowano optymalny interfejs graficzny systemu AR.

Słowa kluczowe: rzeczywistość rozszerzona, wyświetlacz przezierny, interfejs graficzny, symulacja, percepcja, czas reakcji 


\section{Introduction}

Augmented reality (AR) is a system that adds virtual, interactive elements to the real world. It is used in many fields, including the automotive industry.

A visualisation method used for AR systems is the head-up display (HUD). These displays were first used in military aviation and have since become standard equipment for commercial aircraft. In 1988, they began to be used in the automotive industry. Recently, the trend has been to use them in both luxury and sports cars, as well as in mid-size cars.

There are many kinds of automotive head-up displays that are currently available on the market. The most notable are those that are an integral part of the car, portable displays, and smartphone applications. The latter enables a HUD mode for the navigation system and can work with both Android and iOS operating systems. However, the burning question of how to correctly design a graphical user interface (GUI) for HUD is still discussed in many papers, e.g. [2] and [11]. This question is a valid one, since poor design of the HUD's graphical user interface may distract the driver thus creating a potentially hazardous situation.

Motivated by the rapid growth of the automotive head-up display market and the problems that their correct design pose, it was deemed necessary to conduct a simulation study of the head-up display's GUI and its influence on driver perception and reaction time (RT).

Conducting perception and reaction time research requires several steps. First, various graphical user interfaces were designed using Photoshop Portable software. Photos were then taken in traffic from the perspective of the driver. Following this, the photos and GUI designs were then merged in order to simulate a car interior with a working HUD system. Completing those steps allowed the creation of slides that were then shown to the test subjects. The slides, created in PowerPoint, presented the road and the traffic with the GUIs added to the windscreen.

To investigate the driver's perception, eye-tracking software called GazeRecorder was used. Finally, the results of the tests were used to develop an optimal graphical user interface of an automotive head-up display.

\section{Research methodology}

The analysis of various sources dealing with both the designing of the GUI for head-up displays $[1,4,6,8]$ and the psycho-technical assessments $[2,3,10,11]$ was essential for the research.

Automotive HUDs present valuable information to the driver, including: vehicle speed, data from the tachometer, various alerts and warnings, navigation clues, gear position etc. Some manufacturers decide to include information about temperature, radio settings and notifications about incoming wireless calls. Data is projected on the windscreen, directly within the driver's field of view [3].

Many things have to be taken into consideration while developing the GUI for a HUD. Since the information is displayed on the windscreen, it may cause a potentially hazardous 
situation for the driver. For example, data could clutter the windscreen or obscure the driver's view, or poorly designed icons could confuse the driver at a crucial moment. The ways in which a HUD affects driver perception and its influence on a driver's decision making remains a matter of study [11].

Despite the risks described above, there are undisputed merits to using head-up displays. One such merit is that head-up displays are superior to head-down displays (HDD) since the driver observes the dashboard instruments without looking down and can instead focus on the road ahead. This is especially important for young or inexperienced drivers as it reduces stress levels and improves control over the vehicle. Furthermore, using a HUD instead of a HDD can improve the reaction time of the driver. For some people, HUDs are also more intuitive to use [11].

Evidence exists that HUDs may influence the driver's perception and their ability to avoid collisions $[2,3,10]$. Thus, it is important for the data presented by the HUD to be subtle, meaningful, timely and non-distracting, and to serve its intended purpose without endangering or inconveniencing the driver.

Several sources were found in the literature that present methods for the psycho-technical assessment of drivers. Medical examinations and eye-tracking methods are used to determine perceptual functions. Medical examinations are designed to measure visual acuity, field of view and colour discrimination; however, these are not able to evaluate important elements of perception, such as accuracy and quickness [1]. Eye tracking allows for objective assessment of perceptual processes that occur through the recording of eye focus and eye movements [9].

One of the components of perception is reaction time (RT). A common method for measuring driver's reaction time is the use of test tracks and selected sections of road. Other methods include: 1) observation of the driver in actual traffic conditions, 2) tests in driving simulators, 3) stations for the psycho-technical assessment of drivers [3, 4].

The use of test tracks and observation in actual traffic conditions are the most accurate methods of driver psycho-technical assessment as they reflect the actual responses of the driver. The difficulties in performing tests are the coordination of the test, the potential lack of repeatability of conditions, the interpretation of results, and the cost of the research.

A disadvantage of driving simulators and psycho-technical stations is that the environment during testing is artificial. Furthermore, due to the difficulty of accessing such facilities and devices, it is impossible to carry out the research on a large scale. Nonetheless, these methods ensure repeatability of the research and are comfortable and practical for both the person being tested and the person conducting the test [4].

One of the testing systems that deal with the assessment of driver perception and reaction time is the Vienna Test System. It uses the Adaptive Tachistoscopic Traffic Perception Test (ATAVT) for perception assessment and the Reaction Test (RT) to determine driver reaction time. ATAVT mainly analyses the speed of perception; it assesses the speed of identifying objects and patterns. RT investigates attentional functions, and allows the study of both simple and choice reactions. With this method, the unit of measurement is milliseconds. The Vienna Test System station consists of a monitor, a computer with installed tests and external test equipment [8]. 
It was important to decide what is an appropriate number of participants for the study; however, the available sources don't provide a clear answer to that. Nielsen [7], while discussing graphical interfaces, claims that the best results are obtained while examining five users; he argues that this is the optimal number. Every additional person beyond the original five adds too little in the way of new information and affects the economic viability of the study. Five participants are able to provide around $75 \%$ of viable information on the usability of the interface.

Nielsen's chart presenting the proportion of the percentage of usability problems to the number of participants is shown below [7].

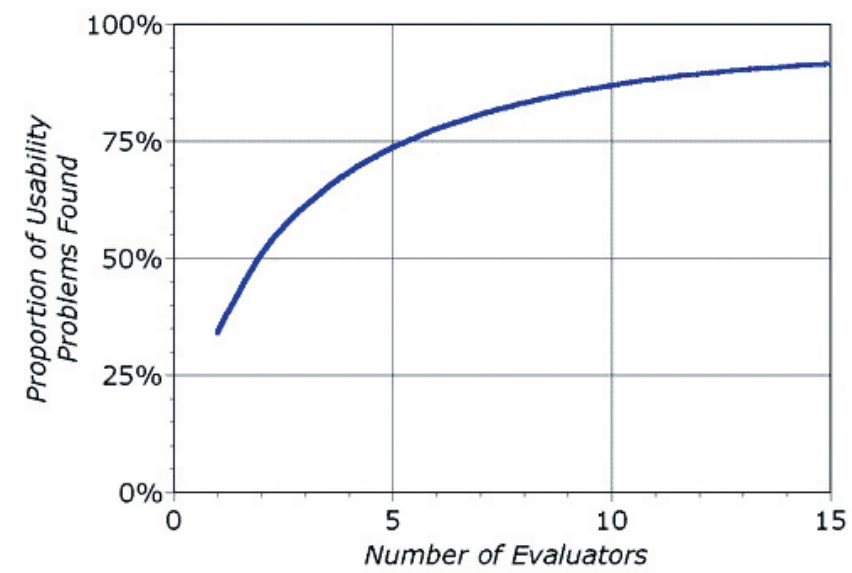

Fig. 1. Nielsen's proportion of usability problems in an interface found by heuristic evaluation using various numbers of evaluators [7]

Evaluating the usefulness of AR systems can be performed through the use of survey techniques. This is a valuable method and can be easily conducted in a chosen group of respondents to assess the general perception of the designed GUI [5].

After analysing current research methods, the following steps were taken: 1) A suitable procedure was selected, 2) the proposed GUI variants were developed, 3) the research station was created, 4) a test group was chosen.

\section{The research station and the examined group of people}

The simulation was conducted on a group of seven participants. This group was made up of both male and female drivers aged 23-26. All participants had a category B driving licence, some members also had A and C driving licence categories. Every participant also passed valid medical exams for drivers and their eyesight was classified as either good or corrected to normal (eyeglasses or contact lenses). Taking everything into consideration, it was decided to create a research station for both the reaction time and perception assessment. 
Simulation methods were used to acquire results for both the perception and the reaction time studies. For the simulation, various slides were used; these depicted different situations on the road with the head-up display added. The proposed variants of the HUD's graphical user interface were developed using Adobe Photoshop Portable. It was important to simulate the interior of the car with a working see-through display; thus, the photos were taken from behind the wheel. It was decided to use two different cars, a Peugeot 207 and a Ford Fusion, since there are differences in the size of their windscreens and their fields of view.

Previously developed designs were added as layers to the photo, using Adobe Photoshop Portable. Complete images were then transferred to Microsoft PowerPoint. Thus, the slides designed for the simulation were finally ready to be presented to the test group at the research station. The station consisted of a 15.6" HP Pavilion notebook with a webcam and two stopwatches.

The notebook was equipped with the GazeRecorder eye-tracking software program, which could also generate the dynamic and static heat maps of the gaze. Stopwatches which were accurate to one one-hundredth of a second were used to measure the reaction time.

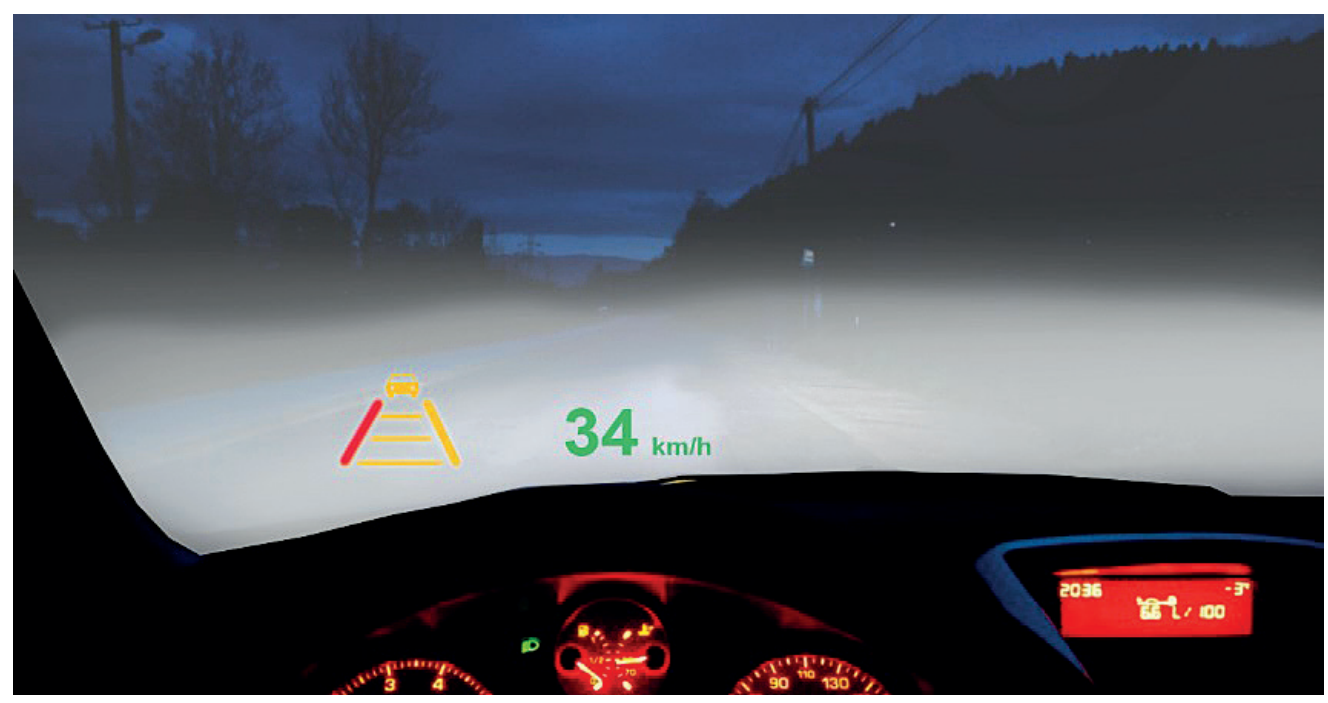

Fig. 2. An example of a simulated situation

\section{The study of simple reaction time}

The simulation study of driver reaction time consisted of ten traffic situations. Because it was important to check the driver's reaction time on an unexpected situation, the display shown either an alert or a warning information. Donders' subtractive method was used to correctly measure the time. In this case, both the person responsible for conducting the simulation and the person being tested had stopwatches. The time marked on the stopwatch of the tested person was subtracted from the time marked on the stopwatch of the researcher. Thus, the acquired result is the reaction time for the displayed stimulus. 
The prepared research station enabled the presentation of twenty slides: ten different road situations without the GUI displaying an alert and ten with an alert. The slides were shown at various time intervals and the variant without the GUI and the variant with the GUI were presented alternately. The stopwatch was activated at the same time that the new situation was displayed. The driver under assessment had to stop it only after noticing and understanding an alert. At the same time, the researcher measured the actual time of displaying the alert on the second stopwatch. Both results were written down and then subtracted. The final result is the actual reaction time. The test was carried out with an accuracy of $1 / 100$ of a second. The average reaction time of all people being tested was $0.823 \mathrm{~s}$. One second is considered to be the classic value for the reaction time of a driver in ordinary conditions [1]. Taking this value into consideration, it should be noted that the average result of $0.823 \mathrm{~s}$ is a very good outcome.

Table 1. An example of a result of the RT study

\begin{tabular}{|c|c|}
\hline $\begin{array}{c}\text { Number of the } \\
\text { situation }\end{array}$ & Reaction time \\
\hline 1 & 0.47 \\
\hline 2 & 1.33 \\
\hline 3 & 1.21 \\
\hline 4 & 1.11 \\
\hline 5 & 1.01 \\
\hline 6 & 1.19 \\
\hline 7 & 1.27 \\
\hline 8 & 0.99 \\
\hline 9 & 0.52 \\
\hline 10 & 1.23 \\
\hline
\end{tabular}

On the basis of the conducted reaction time study, it was observed that the configuration of the head-up display and the proper presentation of data may reduce the reaction time of respondents.

\section{The study of perception}

The driver's perception was examined using the eye-tracking method. This allows determining not only where the gaze focuses but also for how long.

The test was conducted using fourteen slides, designed expressly for the testing. These slides depicted different road situations with the interface of the augmented reality system added. Each slide was presented to the assessed participant for precisely seven seconds. During every testing session, various dynamic heat maps of the gaze were recorded. This was possible due to the use of the GazeRecorder software and a notebook computer equipped with a webcam. As it was important to get the most precise results of the examination, GazeRecorder was calibrated individually for each assessed participant. 


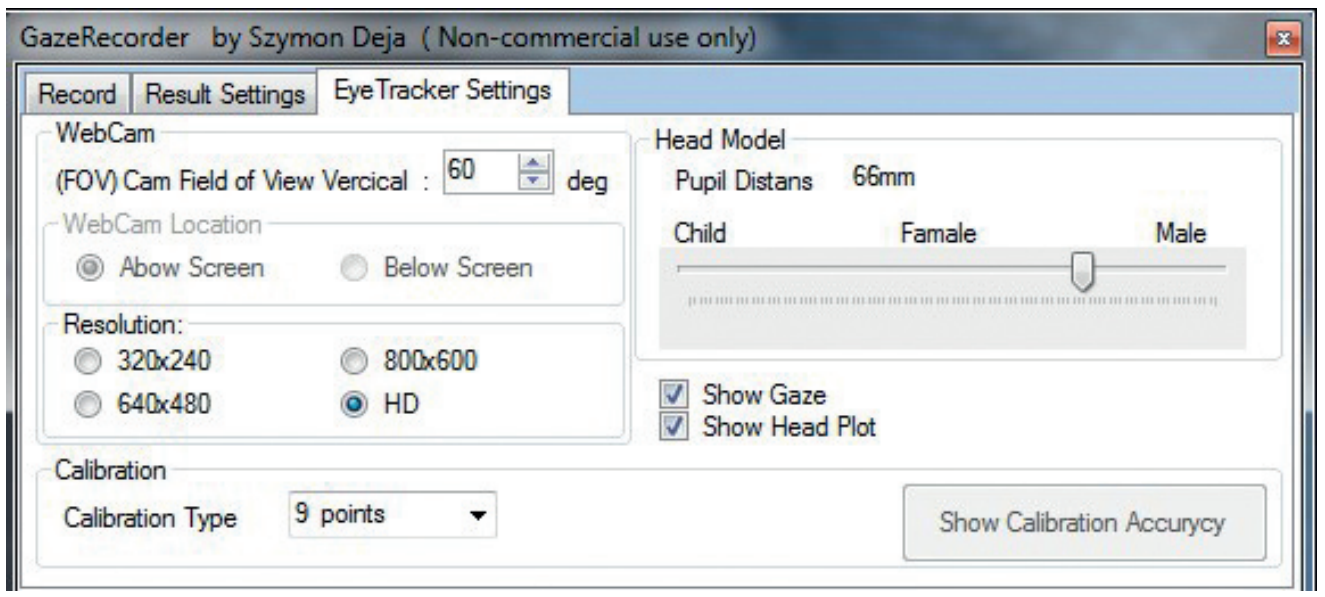

Fig. 3. Calibration settings used in the GazeRecorder software

The following settings were used: 1) the calibration was performed at nine points on the screen, and 2) the interpupillary distance was set. Individuals with refractive errors were able to state their actual interpupillary distance For those with emmetropia, it was decided to use the average interpupillary distances of $63 \mathrm{~mm}$ for women and $66 \mathrm{~mm}$ for men. The data were processed by the software at intervals of $200 \mathrm{~ms}$. The video was recorded at a resolution of 1366 x 768 pixels (15.6" screen). The average time for testing each assessed participant was around two minutes. This period does not include the time needed to calibrate the GazeRecorder software.

The following step was to generate static heat maps of the gaze. These were generated on the basis of previously recorded dynamic heat maps. The testing generated ninety-eight static heat maps and seven dynamic heat maps. The map is interpreted in the following way: the warmer the colour, or the more red on the map, the longer the viewer focused their gaze on the spot in relation to the total time spent looking at the slide. Red indicates the longest time the viewer focused their gaze on the spot, green indicates the shortest. The obtained results show whether elements of the interface were spotted and for how long the viewer focused their gaze on them [9]. The Photoshop Portable's feature that allows the creation of layers was then used to obtain the general maps of the perception. It was important not to cloud the results; thus, for each slide, only the most representative three heat maps were layered. When more layers were used, the bottom layer was either completely invisible or its hues were altered. The alteration of hues was also considered to be damaging for the final results of the testing. In the end, the forty-two most representative static heat maps were used to create fourteen general heat maps.

During the interpretation of the results, it was taken into consideration that the software could interpret spots in error and that the human field of view includes more than just the point upon which the gaze is focused. The results show whether the element of the interface was noticed and for how long the assessed participant observed it. After testing, all participants completed a survey and answered eight questions regarding GUIs. The results of the survey demonstrate, amongst other things, that most participants deem HUDs to be necessary element of a car's dashboard. Moreover, the respondents' general assessment was that both 
their reaction time and perception was influenced by the presented GUI. They also expressed an opinion that the design of the GUI and the presentation of data may be an essential factor influencing driver safety.

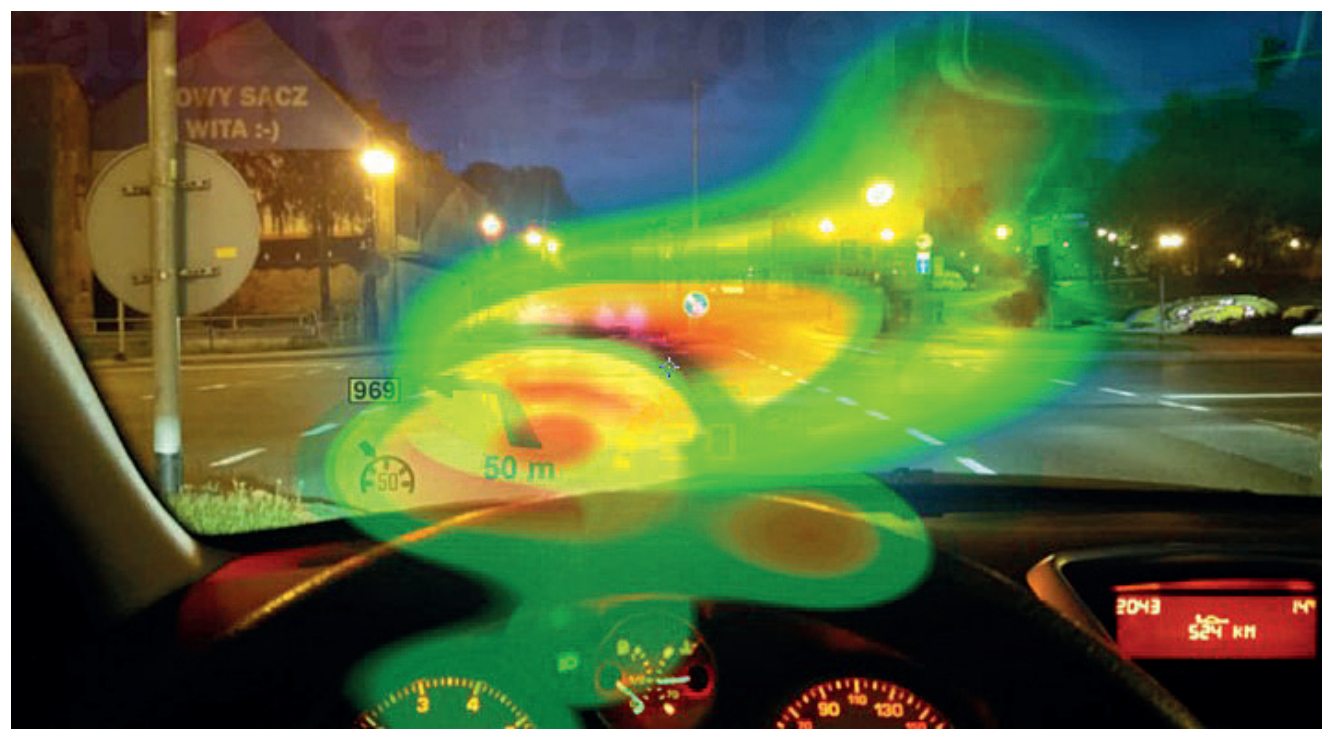

Fig. 4. An example of the general static heat map of a simulated situation

Table 2. The elements which the head-up display should contain according to the participants

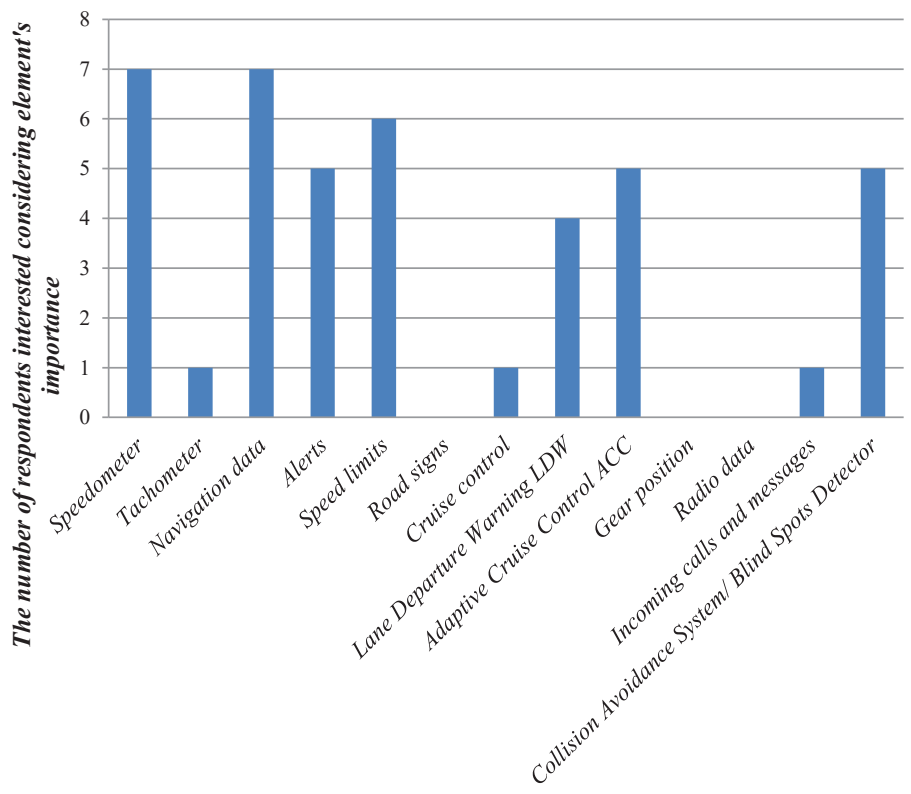


On the basis of the study and the survey, it was confirmed that driver perception is influenced by the way in which the data is presented on the display. Both colour and size of icons as well as the configuration and the position of the element are important. The positioning at the centre above the steering wheel is also important. This way, the driver always looks at the road ahead of them. It is worth noting that positioning the interface too high is undesirable. This is just one of many ways in which the GUI may be designed incorrectly. Interface elements that are positioned incorrectly can obscure the field of vision and thereby endanger the driver and their passengers.

To summarise, the perception study proved that the configuration of the AR system's graphical user interface may influence driver perception.

\section{Designing an optimal graphical user interface for the display}

On the basis of the results from the conducted study, the optimal graphical user interface of the AR system was developed. This was created using the GUI's designs that were created for the study. The analysis of the study results influenced the way in which the display's data is presented as well as its shape. The idea behind this project was the creation of an interface that will improve both driver safety and driving comfort.

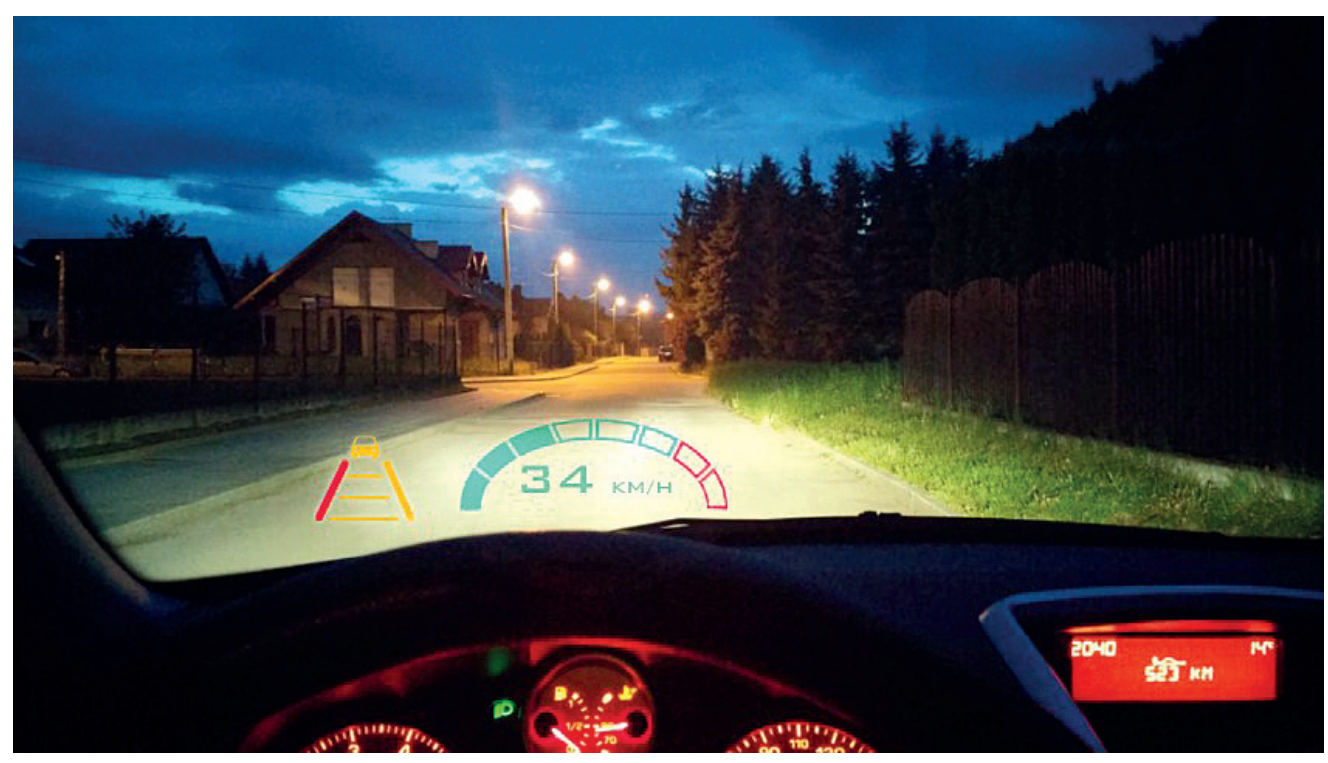

Fig. 5. The design of an optimal graphical user interface - at twilight

It was therefore decided to reduce the number of colours used to only four: teal for the speedometer and tachometer; bright blue for navigation tips; yellow for warnings; red for alerts. In addition, the colours displayed are black and white, as the auxiliary colours for the information displayed by the navigation system and for the speed limits. It was decided to 
create three modes for the GUI: standard, navigation and user's. Note that for safety reasons, it is not possible to display more than four pieces of information simultaneously.

In standard mode, the displayed pieces of information are the speed of the vehicle and speed limits on the road. In the event that the speed limit is exceeded, the colour of the speedometer changes form teal to red.

In navigation mode, the navigation cues are displayed in addition to the speedometer and the speed limits. The bright blue colour is used as it is clearly visible during both the day and at night.

The idea behind the user's mode was to allow the driver to customise the content of the display. In this mode, the only obligatory indicator is the speedometer; the remainder can be freely turned on and off.

The options available for the user to choose are the tachometer, alerts, and the following indicators: speed limit, LDW, ACC and Collision Avoidance System.

a)

$10095 \mathrm{KM} / \mathrm{H}$

b)
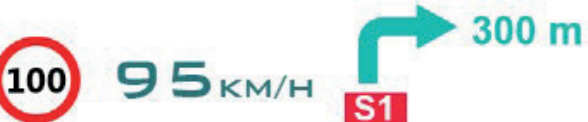

c)
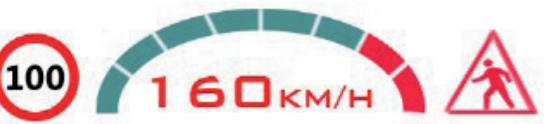

Fig. 6. Three modes of the designed GUI: a) standard, b) navigation, c) user's

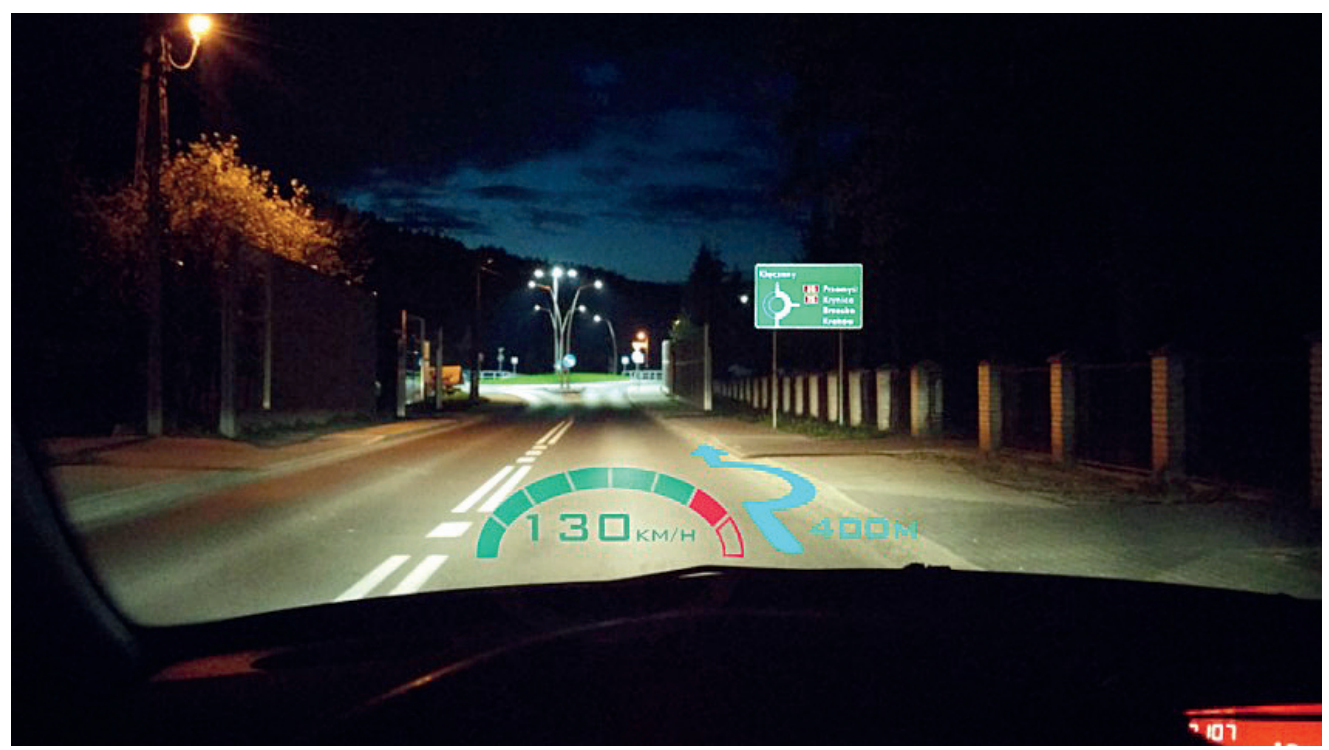

Fig. 7. The design of an optimal graphical user interface at night 
Each segment on the tachometer indicates 1,000 rpm. In the event that the revolutions of the vehicle are too high, the colour of the tachometer changes to red. The range in which it changes is between 6,000 and $8,000 \mathrm{rpm}$.

It seems that the proposed design uses all the cues that resulted from the conducted simulation study as well as the survey. At the same time, it retains the requirements of readability and accessibility for the user. Thus, it could guarantee not only the retain but even the increase of safety and driving comfort.

\section{Conclusions}

On the basis of the conducted perception and reaction time study, the assumption was confirmed that the configuration of the head-up display's graphical user interface may influence both the reaction time and the degree of perception of the respondents.

The results were used to design the optimal graphical user interface for the head-up display. The final concept was based on the designs created for the study.

The analysis of the results influenced the way the GUI's data was presented. The final content of the display: the speedometer, tachometer, navigation system, alerts etc., was the result of the survey completed by the participants.

The aim of this project was the creation of an optimal graphical user interface of an AR system (in this case, the head-up display), one that would contribute to both safety and driving comfort.

The direction of further research will be, amongst other things, the usage of AR systems to improve the working conditions and driving safety of the TIR drivers. It is particularly important to eliminate blind spots in the truck's cabin. This can be achieved using augmented reality and see-through displays. It is possible to use information from omnidirectional cameras (also known as 360-degree cameras) for this purpose.

\section{Acknowledgments}

Presented research was carried out within the confines of the grant for science awarded by the Ministry of Science and Higher Education, No: M-10/174/2016/DS

\section{References}

[1] BąkJ., Psychologiczne badania kierowców, Bezpieczeństwo Pracy 6/2004, 12-15.

[2] Charissis V., Naef M., Papanastasiou S., Patera M., Designing a Direct Manipulation HUD Interface for In-Vehicle Infotainmen, [in:] Human-Computer Interaction. Interaction Platforms and Techniques. HCI 2007, Lecture Notes in Computer Science, vol. 4551., eds. J.A. Jacko, Springer, Berlin, Heidelberg 2007, 551-559.

[3] Charissis V., Naef M., Arafat S., Vlachos G., On the Impact of User's Computer Knowledge on Driving Simulation Test Results - HUD Simulation Case Study, Proceedings of the 
European Annual Conference on Human Decision-Making and Manual Control, EAM'08/2008.

[4] Guzek M., Kobylański K., Badanie czasu reakcji kierowców z wykorzystaniem urządzenia MCR-2001E., Prace Naukowe Politechniki Warszawskiej, Transport 96/2013, 191-199.

[5] Konopacki J., The technology of augmented reality - virtual reconstructions of landscape architecture design, Technical Transactions vol. 5-A/2014, 98-105.

[6] Merkisz J., Galant M., Orszulak B., Badanie wptywu treningu symulatorowego na czas reakcji kierowcy, Logistyka - Nauka 6/2014, 7293-7299.

[7] Nielsen J., Landauer T. K., A mathematical model of the finding of usability problems, [in:] Proceedings of the INTERCHI ' 93 conference on Human factors in computing systems, eds. S. Ashlund et al., ACM, New York 1993, 206-213.

[8] Niezgoda M., Kamiński T., Ucińska M., Tokarczyk E., Kruszewski M., Komputerowe systemy wspomagania psychologicznych badań kierowców, Logistyka - Nauka 6/2011, 3027-3034.

[9] Piotrowska I., Okulografia w badaniach postrzegania i konstruowania wiedzy geograficznej, Prace Komisji Edukacji Geograficznej, 3/2014, 175-189.

[10] Rusch, M. L., Schall Jr., M. C., Gavin, P., Lee, J. D., Dawson, D. J., Vecera, S., Rizzo, M., Directing driver attention with augmented reality cues, Transportation Research, Part F/2013, 127-137.

[11] Smith, S., Shih-Hanh F., The relationships between automobile head-up display presentation images and drivers' Kansei, Displays 32/2011, 58-68. 